\title{
PANDEMIA DA COVID-19: PERCEPÇÕES DE ESTUDANTES DE ENFERMAGEM SOBRE O SEU ENSINO
}

\section{COVID-19 PANDEMIC: NURSING STUDENTS 'PERCEPTIONS ABOUT THEIR TEACHING}

\section{PANDEMIA COVID-19: PERCEPCIONES DE LOS ESTUDIANTES DE ENFERMERÍA SOBRE SU ENSEÑANZA}

\author{
Luís Felipe Pissaia ${ }^{1}$ \\ Arlete Eli Kunz da Costa ${ }^{2}$
}

\begin{abstract}
Resumo
Este estudo possui o objetivo de avaliar as percepções de estudantes de enfermagem sobre o seu ensino durante a pandemia causada pela Covid-19. Trata-se de uma pesquisa qualitativa, descritiva e exploratória, tendo como participantes, treze estudantes de enfermagem de uma Instituição de Ensino Superior do interior do Rio Grande do Sul, Brasil. A coleta de dados ocorreu durante o segundo semestre do ano de 2020, utilizando-se de um questionário aplicado com o auxílio da plataforma Google Formulários. A análise dos resultados seguiu aproximações com a Análise de Conteúdo de Bardin. Identificou-se que os participantes compreendem a necessidade de virtualização nesse momento de pandemia, como maneira de proteção social. Alguns participantes indicaram perda no processo de ensino e aprendizagem. Contudo, todos os participantes compreendem que a virtualização é a melhor opção para o momento de pandemia. Considera-se que este estudo contribui para a problematização sobre o tema, bem como a reflexão para construir novas estratégias e ações de melhoria no processo de ensino e aprendizagem em enfermagem durante a pandemia causada pela Covid-19.
\end{abstract}

Palavras-chave: Pandemia. Ensino. Ensino em Enfermagem. Covid-19.

\begin{abstract}
This study aims to assess the perceptions of nursing students about their teaching during the pandemic caused by Covid-19. It is a qualitative, descriptive and exploratory research, with participants, thirteen nursing students from a Higher Education Institution in the interior of Rio Grande do Sul, Brazil. Data collection took place during the second half of 2020, using a questionnaire applied with the help of the Google Forms platform. The analysis of the results followed similarities with the Bardin Content Analysis. It was identified that the participants understand the need for virtualization in this pandemic moment, as a way of social protection. Some participants indicated a loss in the teaching and learning process. However, all participants understand that virtualization is the best option for a pandemic moment. It is considered that this study contributes to the problematization on the theme, as well as the reflection to build new strategies and actions for improvement in the teaching and learning process in nursing during the pandemic caused by Covid-19.
\end{abstract}

Keywords: Pandemic. Teaching. Nursing teaching. Covid-19.

\section{Resumen}

Este estudio tiene como objetivo evaluar las percepciones de los estudiantes de enfermería sobre su enseñanza

\footnotetext{
${ }_{1}$ Possui Graduação em Enfermagem, Mestrado em Ensino e desenvolve. Doutorado em Ensino pela Universidade do Vale do Taquari - Univates. Especialização em Gestão e Auditoria em Serviços da Saúde e Enfermagem do Trabalho pela Faculdade Futura. É docente vinculado ao Núcleo de Educação Continuada e Extensão da Universidade do Vale do Taquari - Univates. ORCID: https://orcid.org/0000-0002-4903-0775 E-mail: Ipissaia@universo.univates.br

2 Possui graduação em Enfermagem - Licenciatura Plena pela Universidade do Vale do Rio dos Sinos (1988), graduação em Enfermagem e Obstetrícia pela Universidade do Vale do Rio dos Sinos (1988), mestrado em Desenvolvimento Regional pela Universidade de Santa Cruz do Sul (2003) e doutora em Ambiente e Desenvolvimento pelo Centro Universitário Univates (2016). Atualmente é professora titular da Universidade do Vale do Taquari -Univates. ORCID: https://orcid.org/0000-0002-5655-3646 E-mail: Ipissaia@universo.univates.br
} 
durante la pandemia causada por Covid-19. Se trata de una investigación cualitativa, descriptiva y exploratoria, con participantes, trece estudiantes de enfermería de una Institución de Educación Superior en el interior de Rio Grande do Sul, Brasil. La recolección de datos se realizó durante el segundo semestre de 2020, mediante un cuestionario aplicado con la ayuda de la plataforma Google Forms. El análisis de los resultados siguió similitudes con el análisis de contenido de Bardin. Se identificó que los participantes comprenden la necesidad de la virtualización en este momento pandémico, como una forma de protección social. Algunos participantes indicaron una pérdida en el proceso de enseñanza y aprendizaje. Sin embargo, todos los participantes comprenden que la virtualización es la mejor opción para un momento de pandemia. Se considera que este estudio contribuye a la problematización del tema, así como a la reflexión para construir nuevas estrategias y acciones de mejora en el proceso de enseñanza y aprendizaje en enfermería durante la pandemia provocada por Covid-19.

Palabras clave: Pandemia. Enseñando. Docencia en enfermería. COVID-19.

\section{INTRODUÇÃO}

A pandemia da Covid-19 mostrou os primeiros sinais de transmissão na China em meados de dezembro do ano de 2019 e, poucas semanas após iniciaram as ações de contenção do novo vírus que demonstrava um grande potencial de transmissão entre as pessoas, indica Souza (2020). Ainda, neste sentido Ripa (2020) e Santos et al. (2020) não demorou muito e os casos se espalharam pelos países vizinhos, ganhando ênfase no continente europeu, onde a mortandade tornou-se representativa, mesmo com as ações implantadas de contenção e assistência em saúde.

Para Rossoni (2020) a estruturação de espaços de atenção à saúde e apoio a rede de terapia intensiva se mostraram eficazes, contudo a demanda crescente superlotou as instalações que em poucos dias entraram em colapso. As notícias vindas dos países desenvolvidos, principalmente do continente europeu demonstravam a exacerbação dos casos confirmados da Covid-19 e a incapacidade dos serviços de saúde em atuar frente a crise de saúde (PEREIRA, 2020).

Segundo Santos et al. (2020), nos primeiros meses de 2020, a Covid-19 chegou ao Brasil, já denominada como pandemia e assumia um caráter amedrontador dentre a população que até então não assimilava a necessidade de cuidados preventivos para a contaminação. Conforme Azevedo e Simões (2020), os primeiros casos foram acontecendo no país, as autoridades implementaram ações de isolamento social como estratégia de redução na transmissão do vírus.

As medidas de distanciamento social soaram com descredito perante algumas classes da sociedade brasileira, possuindo dificuldades de compreensão pelo governo federal e entidades apoiadoras do grupo político (RAFAEL et al., 2020). Segundo Ripa (2020) a 
polarização política no Brasil dificultou a tomada de decisão imediata, fragmentando as ações direcionadas à federação e obrigando os governos estaduais a assumirem a gestão plena dos estados e municípios sob sua gestão.

Dentre as ações de distanciamento social, estavam a suspenção de atividades educativas presenciais, no que tange o fechamento das instituições de ensino, independente do nível, para evitar possíveis aglomerações, lembram Scoz e Melchioretto (2020). As Instituições de Ensino Superior (IES) receberam essa demanda e se viram obrigadas a encontrar alternativas para permanecer com as atividades mesmo com o distanciamento social necessário em função da pandemia (ROSSONI, 2020).

Para Azevedo e Simões (2020) as IES reagiram prontamente aos primeiros sinais de crise sanitária que levantava sob o horizonte brasileiro, suspendendo ou buscando ações de proteção dos indivíduos e manutenção dos processos de ensino e aprendizagem. Os esforços coletivos das IES demonstraram o compromisso social em que essas instituições assumem perante uma crise (SANTOS REIS, 2020).

As ações imediatas para o seguimento das atividades de ensino, foi a virtualização das aulas, implementando ferramentas de áudio e vídeo que suprissem a demanda por contato direto entre os docentes e os estudantes, é indicado por Santos Reis (2020). Para Rossoni (2020), além das aulas, as atividades administrativas também foram virtualizadas, possibilitando a realização do trabalho remoto em formato de home office.

As atividades em home office foram a alternativa capaz de manter boa parte dos empregos ativos e da segurança dos grupos familiares ligados principalmente as empresas (PEREIRA, 2020). Mesmo assim, outros setores sofrem com as dificuldades em manter as atividades no momento de pandemia, como no caso de indivíduos autônomos ou que dependem do contato direto com a população para exercer suas atividades, conforme comentam Azevedo e Simões (2020).

A virtualização das disciplinas segue a premissa de disponibilidade dos conteúdos necessários para o estudante, minimizando os impactos da suspensão das atividades presenciais em decorrência da pandemia, indicam Honorato e Nery (2020). Na área da saúde, as disciplinas teóricas seguiram o limiar de utilização de plataformas de vídeo e amparadas pelos Ambientes Virtuais de Aprendizagem (AVA) que possibilitaram a aproximação entre o estudante e a IES, comenta Pereira (2020). 
A maior parte das IES possuem AVAs em funcionamento mesmo antes da crise pandêmica, fato que acelerou a disponibilidade de conteúdo e a continuidade das aulas em ambientes seguros (SOUZA, 2020). Contudo, essa não é uma realidade presente em todo o território brasileiro, fato que comprova o alto nível de desigualdade social e incapacidade financeira das esferas governamentais em suprir a demanda emergencial de tecnologias, conforme comenta Rossoni (2020).

Contudo, algumas disciplinas não puderam passar pela virtualização, pelo menos integral, como no caso daquelas que são práticas ou que são caracterizadas como estágios curriculares, define Santos Rocha (2020). Para Souza (2020) esses tipos de disciplina foram suspensos temporariamente ou alterados os campos de realização da prática, observando a quantidade de estudantes e os cuidados necessários para a redução da contaminação com o vírus.

Na enfermagem em específico, o ensino sofreu o impacto direto da pandemia da Covid19. O curso é conhecido pela amplitude prática, uso de laboratórios e realizações de estratégias de ensino que permitam a experimentação acadêmica. E, com a virtualização das disciplinas, muitas estratégias de ensino necessitaram de reformulação para contemplar o desenvolvimento das habilidades e competências dos estudantes, indica Santos Rocha (2020).

No cenário apresentado, Azevedo e Simões (2020) comentam que há dificuldades não somente na adaptação das disciplinas, mas também no acesso dos professores às ferramentas tecnológicas e de redes sociais. Para Martins (2020) a métrica alcançada de estudantes em disciplinas virtualizadas só foi possível com o empenho das IES em capacitar o corpo docente sobre as ferramentas digitais disponíveis no mercado e sua contextualização com as estratégias de ensino pertinentes ao momento.

Dessa forma, compreende-se que a pandemia da Covid-19 ocasionou diversas modificações nos padrões sociais e na maneira como o ser humano observa o planeta. Por esse motivo, justifica-se a necessidade de buscar evidências científicas que abarquem essas alterações no período que compreende a pandemia, refletindo sobre os achados e buscando um legado duradouro. Assim, torna-se pertinente o objetivo de avaliar as percepções de estudantes de enfermagem sobre o seu ensino durante a pandemia causada pela Covid-19. 


\section{MÉTODO}

Trata-se de uma pesquisa qualitativa, descritiva e exploratória. Os participantes da pesquisa foram 13 (treze) estudantes regularmente matriculados na disciplina de Exercício Profissional de uma IES do interior do estado do Rio Grande do Sul, Brasil.

A disciplina de Exercício Profissional faz parte do currículo do curso de graduação em enfermagem, possuindo como preceito as reflexões sobre as legislações vigentes para a atuação em enfermagem, bem como a observação sobre as necessidades do profissional. Dentre os conteúdos estudados, merece destaque a atenção aos aspectos contemporâneos de uso de tecnologias e acontecimentos sociais que impactam diretamente na comunidade onde os indivíduos estão inseridos.

A disciplina ocorreu no segundo semestre de 2020, mesmo período temporal em que ocorreu a coleta de dados. O instrumento de coleta de dados foi à aplicação de um questionário online, utilizando a ferramenta de Formulário do Google. A ferramenta possibilitou a realização de perguntas abertas sobre o sentimento dos estudantes perante a virtualização das disciplinas as quais estavam matriculados e o seu ensino durante a pandemia da Covid-19.

Os resultados foram registrados na própria ferramenta de Formulário do Google e transcritos para um documento de edição em formato de Word para a análise. A análise dos resultados seguiu aproximações com a Análise de Conteúdo proposta por Bardin (2016). Inicialmente as informações foram compiladas para uma avaliação ampla dos achados, seguido da divisão por pontos focais e posterior junção e m categorias temáticas.

A análise proposta buscar analisar todos os achados igualmente de maneira imparcial e sua divisão em pontos focais, os quais se destacam pela semelhança nos conteúdos. Os agrupamentos por pontos focais originam as categorias temática do estudo, as quais permitem a construção de diferentes analises e discussões pertinentes.

Para a realização do estudo, foram seguidos os critérios éticos para pesquisas com seres humanos indicados pela Resolução 466 de 2012 do Conselho Nacional de Saúde (BRASIL, 2012). Antes da disponibilização do questionário, os estudantes foram informados dos preceitos éticos que envolvem a pesquisa, indicando os objetivos e a sua posterior divulgação em formato de textos científicos. Todos os participantes responderam ao Termo de Consentimento Livre e Esclarecido (TCLE) disponível no próprio Formulário disponibilizado aos 
estudantes. Como parte dos critérios éticos da pesquisa, a identidade dos participantes foi preservada como o uso de codinomes, sendo indicados no texto pela letra "E" seguida de números ordinais sorteados.

\section{RESULTADOS E DISCUSSÃO}

Nesta seção são apresentados os resultados e as discussões referentes à pesquisa realizada, sendo subdivididos em duas categorias temáticas. A primeira categoria é denominada como "Sentimentos perante a virtualização das disciplinas" cujo contexto espelha a realidade vivenciada pelos estudantes do curso de graduação em enfermagem no momento da pandemia da Covid-19. A segunda categoria é intitulada "Entraves da virtualização das disciplinas para a enfermagem", espaço destinado para registrar as situações problema que surgiram com a virtualização das disciplinas, bem como as nuances de sentimentos dos participantes perante o momento atual.

\section{Sentimentos perante a virtualização das disciplinas}

Nesta categoria, são apresentados os sentimentos relatados pelos participantes da pesquisa em relação à virtualização das disciplinas, de modo que seja compreendida a realidade enfrentada pelos estudantes. Acredita-se que ao observar a ocorrência das situações que permeiam o período da pandemia da Covid-19 é possível articular meios de melhoria nos processos de ensino e aprendizagem, bem como uma melhor concordância com as necessidades dos participantes da pesquisa.

Os participantes demonstraram a necessidade de se reinventar perante a pandemia e acreditam que a virtualização seja a melhor alternativa para o momento, como E4 indica: “Bom pelo lado de não termos parado, pois seria pior e também ao mesmo tempo preocupante pois presencial aprendemos mais". Mesmo assim, percebe-se que sob o olhar do estudante 0 ensino presencial se torna mais eficaz. O participante E7 comenta: "Acredito que todos tivemos que nos reinventar, sinto falta do contato com a sala de aula, acho tudo muito estranho, mas acredito que estamos indo bem". Já sob o ponto de vista da participante $\mathrm{E} 7$, o ensino esta evoluindo bem neste formato. Dessa forma, percebe-se que os participantes se encontram preocupados com o acontecimento da pandemia da Covid-19, compreendendo a necessidade de articular alternativas pertinentes ao momento e que supram as necessidades de contato com a IES. A necessidade de virtualização do ensino, mesmo que com o uso de ferramentas da internet, acabam por deixar lacunas nas expectativas dos estudantes, favorecendo a 
insatisfação e até mesmo a ocorrência de possíveis perdas na qualidade da formação (BRASIL, 2020). Para Gomes et al. (2020) a virtualização torna-se uma alternativa importante e necessária no momento da pandemia da Covid-19 e mesmo com a perde do contato físico, as discussões e a construção do conhecimento permanecem acontecendo no período de distanciamento.

Alguns estudantes citam o fato de morar a certa distância da IES e depender de transporte público para frequentar as aulas presenciais e que desse modo, a virtualização os protege de possíveis contatos com o vírus. Tal fato pode ser observado no relato de E6: "Uso o ônibus público para ir à universidade, fico nele em média 1 hora e às vezes precisa trocar de veiculo no meio do trajeto, assim as aulas online são melhores nesse momento". E8 complementa: "A minha viagem até as aulas presenciais é de duas horas, isso além de cansativo me deixa exposta ao perigo de contaminação com outras pessoas, assim a universidade pensou em nós também". O participante E10 também comenta: "Estamos ansiosos por um lado pela falta das aulas presenciais, mas de outra forma seguros e protegidos, já que ainda não temos vacinas, muitos usam meio de transporte para se deslocar dos municípios até a universidade, esse seria a minha pior preocupação". Analisando os registros dos estudantes, percebe-se que a aula presencial possui uma cadeia de situações que podem elevar o nível de contato com o vírus da Covid-19, inferindo que para chegar na sala de aula há a necessidade do uso de transporte compartilhado e por consequência o contato com outros indivíduos. Ao virtualizar as aulas, as instituições de ensino buscam articular formas de manter o isolamento social frente a grande disseminação da Covid-19 no Brasil, além de oferecer manter os estudantes seguros e oferecer formas de acesso a formação adequada durante o período, conforme comentam Gallasch et al. (2020) e ICN (2020). Segundo Marques (2020) a continuidade das disciplinas mesmo que virtualizadas demonstra a capacidade das IES em disponibilizarem alternativas ao ensino dos seus estudantes no momento de crise sanitária.

Sob o mesmo limiar, os participantes evidenciam que 0 uso das ferramentas tecnológicas favorece a realização das aulas, diminuindo a distância entre o estudante e docente, conforme comenta E8: "A pandemia veio e não teve alternativa, melhor assim com o Meet do que cancelar todas as disciplinas e atrasar o curso ou até mesmo não aprender nada no período". A disponibilidade da ferramenta de vídeo também foi comentada por E3: "Tenho medo da pandemia e entendo a necessidade de usar as ferramentas nesse momento, seria muito chato estar em sala de aula com medo de pegar o vírus". No início da pandemia da 
Covid-19, a IES possuía uma grande preocupação em relação ao aceite dos estudantes quanto a virtualização das disciplinas, percebendo que há longo prazo foi a melhor escolha, estando em consonância com as necessidades da população e atenda a segurança da comunidade. Segundo Rafael et al. (2020), o potencial de transmissão da Covid-19 acaba por amedrontar as pessoas sobre a interação presencial, principalmente em grandes grupos, colocando a necessidade de incluir estratégias de manutenção do distanciamento social. Para Andrade Carneiro (2020) o distanciamento social é a principal ação de proteção das comunidades, possuindo impacto direto no ensino, mas que se torna necessário ao avaliar o potencial de contagio da população e o aumento nas taxas de óbito registradas no Brasil.

A mudança repentina de uma disciplina presencial para a virtualizada trouxe alguns desconfortos nos participantes, contudo verificam o potencial do docente em conduzir as aulas com qualidade. Tal fato é evidenciado pelo participante E5: "No início foi muito complicado, não tinha domínio sobre o vídeo e às vezes até vergonha de falar e tirar dúvidas, mas todos os professores se mostraram bem abertos e disponíveis a ajudar". Sob o mesmo limiar, E10 cita: "O professor ajudou muito, a turma estava difícil no início, tudo era novo, acho que todos tinham medo e depois engrenamos dessa forma até hoje, ajudou muito a penar diferente sobre a pandemia". Complementando, E9 comenta: "Agora estou mais a vontade, no início foi muito difícil". Conforme verificado nos relatos dos participantes da pesquisa, o grande diferencial na aceitação da mudança das aulas presenciais para a virtualizada está na postura docente em sensibilizar os estudantes sobre a necessidade de manter o distanciamento social e concomitante a isso dispor de um ambiente virtual de segurança para o processo de ensino e aprendizagem. Para Moreira, Henriques e Barros (2020) o ensino em saúde exige estratégias diferenciadas como forma de que os estudantes vivenciem as diferentes nuances da formação, tendo como foco a experimentação em campos de estágios, por exemplo. Conforme Gusso et al. (2020) a experimentação é necessária para a formação profissional na área da saúde, dessa forma a virtualização afastou os estudantes das áreas de práticas de estágio, contudo, conforme os autores destacam, que esta ação é momentânea e necessária ao período.

Os participantes descreveram que o contato direto com os docentes mesmo por meio de ferramentas digitais, possibilita uma boa aprendizagem, ou seja, pactuam que a disponibilidade dos materiais e dos momentos online são proveitosos e dentro do esperado, conforme cita E4: "As aulas são muito boas, o professor sempre segue o horário combinado e parece que o conteúdo rende mais em função de estarmos em casa e não ter a função de sair antes ou ficar conversando nos corredores". Sob o mesmo limiar, E9 cita: "Eu aproveito mais em casa, na 
faculdade sempre tem o intervalo e o pessoal demora pra voltar, atrasa a aula e vai indo assim, aqui em casa é diferente parece que todos são comprometidos". Os comentários dos estudantes demonstram que os momentos de interação virtual são proveitosos e dinâmicos, sendo possível guiar uma aula de qualidade mesmo que nos próprios domicílios. As dinâmicas de aula online favorecem a interação em tempo real entre os estudantes e docente, fato que estimula a construção do conhecimento indiferente do espaço, pois depende de cada um em preparar o ambiente e estar aberto para a aula, conforme comenta Martins (2020). Para Marasca et al. (2020) a virtualização possui a disponibilidade de interação entre o docente e todos participantes da disciplina ou do momento de discussões, dessa forma a tecnologia permanece atraindo a presença e interação entre as pessoas no momento da crise de saúde causada pela Covid-19.

As reinvenções tratadas pelos participantes na realização da aula virtual incluem uma nova postura perante o ensino e a capacidade de aprender determinado conteúdo, sobre isso E1 comenta: "Agora é tudo diferente, não tem mais a parte presencial, assim precisamos sempre estudar mais em casa, fazer leitura, ver vídeos e buscar algumas informações extras para complementar a aula". Sob o mesmo limiar, E7 descreve: "Sempre leio os artigos de apoio à aula e ajuda muito a entender o conteúdo, não fazia isso antes e acho que aprendo mais agora com a aula online em casa". Sob o mesmo limiar, E2 comenta: "Assisto a aula e às vezes tenho vergonha de perguntar as coisas para o professor, então leio muito depois e busco os materiais de apoio na aula para aprender o conteúdo". Conforme observado nos relatos dos participantes, há uma preocupação em buscar conteúdos extras, além daqueles apresentados pelo docente no momento da aula, sendo possível perceber os benefícios do empenho e compromisso com a construção do conhecimento. Para Gorgens e Andrade (2020) o aproveitamento das aulas depende da motivação e interesse do estudante em dar seguimento ao seu processo de ensino e aprendizagem buscando articular, meios complementares que qualifiquem aquilo que é trabalhado em sala de aula. Conforme Oliveira e Chaves (2020) e Ferla et al. (2020) a motivação dos estudantes na busca por conhecimento complementar a sala de aula é necessária para a formação de qualidade mesmo que em período de incertezas e mudanças impactantes no formato de ensino, fortalecendo não somente a capacidade de flexibilização, mas de resiliência dos indivíduos.

Dessa forma, os participantes da pesquisa aceitam de forma saudável a virtualização das disciplinam em curso no período da pandemia da Covid-19. Os relatos dos participantes, bem como as discussões realizadas durante a construção da categoria demonstraram os 
benefícios da virtualização do ensino em detrimento à proteção dos indivíduos e a preocupação com o bem-estar da comunidade. Compreende-se que as dificuldades existem e impactam diretamente na rotina de virtualização do ensino, mas que a compreensão e colaboração entre os estudantes e IES é mutua e importante.

\section{Entraves da virtualização das disciplinas para a enfermagem}

Nesta categoria são apresentados alguns entraves relacionados à virtualização das disciplinas em específico no curso de enfermagem, de modo que as reflexões pertinentes sejam realizadas. $O$ curso de graduação em enfermagem possui como principal diferencial a realização de experimentações práticas na rede de saúde desde os semestres iniciais e que passaram por mudanças repentinas com a crise de saúde causada pela Covid-19.

Os participantes mencionaram que sentem falta das aulas presenciais, do contato com colegas e pacientes, conforme menciona E4: "As aulas presenciais sempre são divertidas, nós conversamos uns com os outros e trocamos experiência sobre como fazer em conjunto com o professor". Da mesma forma E8 cita: "É legal o presencial, sempre tem trabalhos em grupo, de pesquisa e isso nos deixa integrado com os demais, é ruim agora porque quase ninguém fala nada, comenta com os professores no virtual". E9 complementa: "Por mais que os professores sempre buscam coisas diferentes e maneiras e ensinar, nem sempre estamos motivados a ler o material ou ficar olhando para o vídeo, por isso acho melhor o presencial". Os relatos dos participantes da pesquisa demonstram a carência por contatos presenciais com os colegas de curso e também com a população acompanhada anteriormente durante as práticas e estágios. Compreende-se que uma mudança abrupta nos processos de ensino e aprendizagem acaba por gerar desconforto, não somente por parte dos estudantes, mas do docente também, pois novas situações não são previsíveis e gera a introdução de paradigmas, conforme indica Suárez (2020). Para Valente et al. (2020) o ensino virtualizado serve como modelo substitutivo para o momento de crise causada pela Covid-19, mas em si, representa dificuldades na construção do conhecimento baseado nas premissas de interação entre teoria e prática, principalmente nos cursos relacionados a área da saúde.

Quanto à aprendizagem, alguns participantes comentaram que a aula virtualizada não possui o mesmo aproveitamento do que a presencial, conforme E2 comenta: "[...] sentimentos ruins, pois tenho dificuldade no aprendizado e acabo por me sair mal nas disciplinas". Da mesma forma, E7 descreve: "Por um ponto de vista "inútil" pois a gente não aprende a mesma coisa que se a gente estivesse em uma sala com o professor pessoalmente". E9 complementa: 
"Fico feliz por ter a oportunidade de continuar tendo aula, porém o modo online das disciplinas me deixa mais cansada e me desconcentro com mais facilidade". Ao contrário dos participantes que comentaram os benefícios da virtualização, estes citam a dificuldade em aproveitar os conteúdos no domicílio, intuindo sobre possíveis perdas no processo de mudança ocasionado pela pandemia. Dessa forma, para Guo et al. (2020) percebe-se o descontentamento dos estudantes perante as aulas virtualizadas por não apresentar a mesma aprendizagem do que a presencial, principalmente pela interação gerada com as trocas entre os estudantes. Segundo Vasques e Oliveira (2020) as perdas relatadas pelos sujeitos da virtualização se refere em suma pela perda de contato presencial com os colegas de aula e o professor, dificultando a interação.

Sobre a integração presencial com os colegas e os professores, os participantes mencionaram a dificuldade de interagir com o formato virtual, indicando o sentimento de falta ao lembrar os momentos de trocas de experiências. Sobre esse tema, E6 comenta: "Acho bom e ruim ao mesmo tempo. Bom porque podemos estar no conforto de nossas casas, ou onde nos sentimos confortáveis para assistir a aula e ruim porque perdemos o contanto presencial [...]". O mesmo participante continua relatando sobre a dificuldade na presença dos colegas e do docente: "[...] o contato do professor ali na sua frente, porque nada, nem a tecnologia, por mais que ela seja muito boa, irá suprir a presença de nós alunos e os professores presencialmente na sala de aula". Conforme os participantes mencionam, a interação entre os estudantes é necessária para a troca de informações e experiências, bem como no cultivo de relações sociais de aproximação no espaço acadêmico. Segundo Brasil (2020) a falta de interação gera desconforto aos estudantes, pois as aulas dinâmicas, conversas paralelas e o modelo de parceria presencial acabaram por ruim de forma repentina perante a pandemia, dessa forma compreende-se que os estudantes estejam desconfortáveis com a situação. Para Sampaio (2020) a virtualização é uma necessidade do momento, dessa forma, compreende-se que o distanciamento gera certo grau de dificuldade na compreensão por parte da população, mas que em longo prazo torna-se a melhor alternativa de prevenção da infecção por Covid-19.

Além das aulas presenciais, os participantes mencionam que a suspensão das disciplinas práticas e dos estágios gera preocupação em relação ao atraso no curso e a recuperação desse conteúdo, conforme menciona E3: "Estava com o estágio agendado pra começar uns dias depois que a pandemia começou e isso me deixou triste porque vou ter que recuperar e não sei de que forma, se será proveitoso ou interessante como antes". Da mesma forma, E8 cita: "Algumas disciplinas que matriculei tem a parte prática, no laboratório, mas com 
a suspensão vamos ter que ir em menos colegas e ainda reduzir a quantidade de aulas, fico triste, mas ninguém tem culpa". E12 complementa: "Não tinha como saber que isso aconteceria e agora vamos ter que esperar até a segurança vir e a gente voltar para as práticas normais, isso deixa a apreensão de como será o formato e os cuidados que vamos ter". As incertezas sobre o momento também fazem parte dos dias dos participantes da pesquisa, principalmente por se encontrarem em processo de formação profissional. Os estudantes encontram-se apreensivos sobre a suspensão ou cancelamento temporário das disciplinas práticas e estágios, pois o momento é de apreensão e incertezas sobre o momento em que marcará o retorno e de que forma será a retomada desses momentos, conforme comenta Pereira (2020). Para Silveira et al. (2020) as incertezas sobre a formação dos estudantes é compreensível no momento de crise, mas alternativas devem prevalecer a longo prazo para suprir as necessidades acadêmicas.

Mesmo com os percalços gerados com a virtualização das disciplinas, os participantes compreendem o momento e intuem que é a melhor saída para o momento de pandemia, não só para a proteção individual, mas da população em geral. Desse modo, E4 comenta: "Novidade, buscar adequação e adaptação ao novo modo de ensino. Sinto falta do "calor humano" e das trocas de olhares e conversas". E1 cita: "A pandemia gera muita desconfiança sobre tudo e as aulas no formato virtual estão legais para o momento, é a melhor coisa a se fazer, para nós e para os pacientes que iriamos atender". Sobre o tema, E13 descreve: "Estou observando tudo e acredito que usando essas ferramentas consigo tirar um proveito do momento, é uma situação que todos estão passando e não tem o que fazer". Com base nos relatos dos participantes, percebe-se que a virtualização do ensino é a melhor alternativa para o momento da crise de saúde causada pela Covid-19. Para Santos Rocha (2020) apesar da situação complicada, os participantes compreendem o atual momento de pandemia e indicam a necessidade de manter a virtualização como forma de isolamento social e prevenção da disseminação do vírus. Conforme Clemente e Angeluci (2020) o isolamento social preserva a saúde da população, colocando em primeiro lugar a segurança da comunidade em detrimento as demais atividades, como o ensino que busca alternativas para a continuidade.

Compreende-se que os participantes da pesquisa enfrentam diversas dificuldades nos quesitos de falta de interação com a comunidade acadêmica, sobretudo nas discussões em sala de aula e construção do conhecimento a partir da experimentação. As incertezas sobre o momento geram preocupação por parte dos estudantes, mas acredita-se que a virtualização do 
ensino e o distanciamento social são a melhor alternativa para o enfrentamento da crise de saúde causada pela Covid-19.

\section{CONCLUSÃO}

Este estudo avaliou as percepções de treze estudantes de enfermagem sobre o seu ensino durante a pandemia causada pela Covid-19. Os resultados possibilitam verificar algumas problematizações inerentes a virtualização das disciplinas causada pela pandemia da Covid-19 no ano de 2020.

Identificou-se que os participantes compreendem a situação do momento e a necessidade de manter o isolamento social como forma de prevenir a contaminação em sala de aula ou nos campos práticos e de estágio. Em suma, verificou-se que a virtualização das disciplinas é a melhor saída para o momento, buscando manter o contato entre o estudante e a IES, cumprir com os conteúdos necessários para a formação das habilidades e competências, bem como a interação entre os colegas.

Os participantes indicaram a presença do sentimento de falta das atividades presenciais, sobretudo nas trocas realizadas entre colegas e professores em sala de aula e nas práticas realizadas em laboratório ou demais serviços afins. Alguns participantes indicaram uma perda no processo de ensino e aprendizagem por meio da virtualização das disciplinas de forma abrupta em decorrência da pandemia.

Contudo, todos os participantes compreendem a necessidade de manter as disciplinas virtualizadas nesse momento de pandemia, na busca de auxiliar no isolamento social e proteger a saúde dos estudantes e da sociedade em geram. Dessa forma, o estudo possibilita compreender algumas situações importantes no que tange o ensino em enfermagem nesse período de pandemia, auxiliando para a ciência e na construção de estratégias de melhoria. Mesmo assim, este estudo limita-se em função do número de participantes da pesquisa, limitando a compreensão de uma única realidade, bem como a dificuldade dos autores em encontrar bibliografias nacionais e internacionais que pudessem auxiliar nas discussões.

\section{REFERÊNCIAS}


ANDRADE CARNEIRO, Leonardo et al. Uso de tecnologias no ensino superior público brasileiro em tempos de pandemia COVID-19. Research, Society and Development, v. 9, n. 8, p. e267985485-e267985485, 2020.

AZEVEDO, João Neto; SIMÕES, João Tomaz. A imposição da limitação e a necessidade de um novo trajeto no Turismo. Turismo Mundial, Crise Sanitária e Futuro, p. 79, 2020.

BARDIN, Laurence. Análise de Conteúdo. Tradução: Luís Augusto Pinheiro. São Paulo: Edições 70, 2016.

BOTTINO, Caroline Martins de Melo; SCHELIGA, Eva Lenita; MENEZES, Renata de Castro. Experimentos etnográficos em redes e varandas. Cadernos De Campo (São Paulo 1991), 2020; 29(supl), 289-301. doi: https://doi.org/10.11606/issn.2316-9133.v29isuplp289-301

BRASIL. Conselho Nacional de Saúde. Ministério da Saúde (BR). Portaria 466/2012. Brasília (DF), 2012.

BRASIL. Ministério da Saúde. Secretaria de Vigilância em Saúde. Boletim Epidemiológico 01. Infecção Humana pelo Novo Coronavírus (2019-nCoV). COE № 01 Jan. 2020. Disponível em: $\quad$ https://www.saude.gov.br/images/pdf/2020/fevereiro/04/Boletim-epidemiologico-SVS04fev20.pdf. Acesso em: 27 set. 2020.

CLEMENTE, Adalberto Ortiz; ANGELUCI, Alan César Belo. A CONTRIBUIÇÃO DAS PLATAFORMAS DIGITAIS DE ENSINO, DIANTE DA PANDEMIA. Educere et Educare, v. 15, n. 36.

FERLA, Alcindo Antônio et al. Um paradoxo civilizatório: a pandemia como desafio ao ensino e trabalho na saúde e como afirmação das vidas. Saúde em Redes, v. 6, n. 2 Suplem, 2020.

GALLASCH, C. H. et al. Prevention related to the occupational exposure of health professionals workers in the COVID-19 scenario. Rev. enferm. UERJ.[Internet], v. 28, p. e49596, 2020. doi: http://dx.doi.org/10.12957/reuerj.2020.49596

GOMES, Vânia Thais Silva et al. A Pandemia da Covid-19: Repercussões do Ensino Remoto na Formação Médica. Revista Brasileira de Educação Médica, v. 44, n. 4, 2020.

GORGENS, Pollyanna; ANDRADE, Paulo César. A educação universitária apoiadada pelas tecnologias digitais de informação e comunicação. Revista Eletrônica Científica Ensino Interdisciplinar, v. 6, n. 17, 2020. 
GUO, Xiaodong et al. Survey of COVID-19 disease among orthopaedic surgeons in Wuhan, People's Republic of China. The Journal of Bone and Joint Surgery. American Volume, 2020. doi: http://dx.doi.org/10.2106/JBJS.20.00417

GUSSO, Hélder Lima et al. ENSINO SUPERIOR EM TEMPOS DE PANDEMIA: DIRETRIZES À GESTÃO UNIVERSITÁRIA. Educação \& Sociedade, v. 41, 2020.

HONORATO, Tony; NERY, Ana Clara Bortoleto. História da Educação e Covid-19: a crise da escola segundo pesquisadores africanos (G. Akanbi, L. Chisholm), americanos (C. Boto, A. Cerecedo, M. Cunha, A. Bennett-Kinne, H. Rocha, A. Romano, K. Rousmaniere, M. Southwell, G. Souza, M. Taborda, C. Veiga, D. Acta Scientiarum. Education, v. 42, p. e54998-e54998, 2020. doi: https://doi.org/10.4025/actascieduc.v42i1.54998

INTERNATIONAL COUNCIL OF NURSES (ICN). Guidelines on Advanced Practice Nursing. ICN, 3 place Jean-Marteau, 1201 Geneva, Switzerland. 2020. Disponível em: https://www.icn.ch/system/files/documents/2020-04/ICN_APN\%20Report_EN_WEB.pdf. Acesso em 27 set. 2020.

MARASCA, Aline Riboli et al. Avaliação psicológica online: considerações a partir da pandemia do novo coronavírus (COVID-19) para a prática e o ensino no contexto à distância. Estudos de Psicologia (Campinas), v. 37, 2020.

MARQUES, Ronualdo. A ressignificação da educação e o processo de ensino e aprendizagem no contexto de pandemia da COVID-19. Boletim de Conjuntura (BOCA), v. 3, n. 7, p. 31-46, 2020.

MARTINS, Ronei Ximenes. A covid-19 e o fim da educação a distância: um ensaio. EmRedeRevista de Educação a Distância, v. 7, n. 1, p. 242-256, 2020.

MOREIRA, J. António; HENRIQUES, Susana; BARROS, Daniela Melaré Vieira. Transitando de um ensino remoto emergencial para uma educação digital em rede, em tempos de pandemia. Dialogia, p. 351-364, 2020. doi: http://dx.doi.org/10.5585/Dialogia.N34.17123

OLIVEIRA, Wender Antonio; CHAVES, Sandro Nobre. Os desafios da gestão do ensino superior durante a pandemia da covid-19: uma revisão bibliográfica. Revista de Saúde-RSF, v. 7, n. 2, 2020.

PEREIRA, Luisa Rauter. Conhecimento e comunicação histórica. História da Historiografia: International Journal of Theory and History of Historiography, v. 13, n. 33, p. 13-17, 2020. doi: https://doi.org/10.15848/hh.v13i33.1670 
RAFAEL, Ricardo de Mattos Russo et al. Epidemiologia, políticas públicas e pandemia de Covid-19: o que esperar no Brasil?. Revista Enfermagem UERJ, v. 28, p. 49570, 2020. doi: http://dx.doi.org/10.12957/reuerj.2020.49570

RIPA, Roselaine. Reflexões interdisciplinares sobre a pandemia da Covid-19: um relato de experiência do ciclo de palestras online. Criar educação, v. 9, n. 2, p. 6-28, 2020. doi: http://dx.doi.org/10.18616/ce.v9i2.6042

ROSSONI, Luciano. Covid-19, Organizações, Trabalho em Casa e Produção Científica. Revista Eletrônica de Ciência Administrativa, v. 19, n. 2, p. 158-168, 2020. doi: https://doi.org/10.21529/RECADM.2020ed2

SAMPAIO, Renata Maurício. Práticas de ensino e letramentos em tempos de pandemia da COVID-19. Research, Society and Development, v. 9, n. 7, p. e519974430-e519974430, 2020.

SANTOS REIS, Diego. Coronavírus e desigualdades educacionais: reposicionando o debate. Olhar de Professor, v. 23, p. 1-5, 2020. doi: https://doi.org/10.5212/http://orcid.org/0000-00016977-7166

SANTOS ROCHA, Daniel. Readequação do contexto escolar para o formato remoto em meio à pandemia de Covid-19. Pedagogia em Ação, v. 13, n. 1, p. 263-274, 2020.

SANTOS, Adelcio Machado et al. Tecnologias educacionais em tempo de isolamento social: uma pesquisa com professores. Research, Society and Development, v. 9, n. 9, p. e17996450-e17996450, 2020. doi: https://doi.org/10.33448/rsd-v9i9.6450

SCOZ, Emanuella; MELCHIORETTO, Albio Fabian. Diário de uma professora em crise: adaptações de aulas práticas em dias de isolamento. Investigação Filosófica, v. 11, n. 2, p. 189-203, 2020.

SILVEIRA, Sidnei Renato et al. O Papel dos licenciados em computação no apoio ao ensino remoto em tempos de isolamento social devido à pandemia da COVID-19. Série EducarVolume 40 Prática Docente, p. 35, 2020.

SOUSA, João Baptista Machado. Investigar para transformar: um diálogo necessário frente aos desafios impostos pela Pandemia da COVID-19. RAC: Revista Angolana de Ciências, v. 2, n. 1, p. 01-05, 2020.

SUÁREZ, Noemí. Formación docente universitaria y crisis sanitaria COVID-19. CienciAmérica, v. 9, n. 2, p. 109-114, 2020. doi: http://dx.doi.org/10.33210/ca.v9i2.299 
VALENTE, Geilsa Soraia Cavalcanti et al. O ensino remoto frente às exigências do contexto de pandemia: reflexões sobre a prática docente. Research, Society and Development, v. 9, n. 9, p. e843998153-e843998153, 2020.

VASQUES, Daniel Giordani; OLIVEIRA, Victor Hugo Nedel. Iniciação científica na pandemia: uma análise dos estudos remotos ao ensino fundamental. Interfaces Científicas-Educação, v. 10, n. 1, p. 164-179, 2020. 